\title{
Evaluation of Regenerative Braking Effect for E-REV Bus according to Characteristic of Driving Cycle
}

\author{
Jongdai Choi', Jongryeol Jeong', Yeong-il Park', and Suk Won Cha',", \\ 1 Department of Mechanical and Aerospace Engineering, Seoul National University, 1, Gwanak-ro, Gwanak-gu, Seoul, 151-015, South Korea \\ 2 Department of Mechanical System and Design Engineering, Seoul National University of Science and Technology, 232, Gongneung-ro, Nowon-gu, Seoul, 139-743, South Korea \\ \# Corresponding Author / E-mail: swcha@snu.ac.kr, TEL: +82-2-880-8050, FAX: +82-2-880-1696
}

KEYWORDS: Extended-Range electric vehicle, Regenerative braking torque, Driving cycle, Aggressiveness, Fuel economy

\begin{abstract}
The extended-range electric vehicle (E-REV) is an electric vehicle concept that has a light engine to allow an extended driving range. One of the most important features of these vehicles, based on electricity, is their ability to recover significant amounts of braking energy in a process known as regenerative braking. The more driving motor operates widely as generator, the more braking energy can be absorbed. However, it is not realistic in terms of performance for components. This study proposes three regenerative braking torque maps as the constraints to consider their performance. The results of fuel economy for simulations while applying proposed torque maps are compared with those of simulations without any constraints to evaluate effect of regenerative braking for E-REV bus according to characteristic of driving cycle. The characteristics of driving cycles are analyzed to find relationship between driving cycle and fuel economy. The aggressiveness of the driving cycles shows a linear relationship with regard to the difference in the fuel economy. This result can be used to develop power distribution control strategies with regenerative braking models to improve fuel economy levels.
\end{abstract}

\section{NOMENCLATURE}

Agg = aggressiveness of driving cycle $\left(\mathrm{m} / \mathrm{s}^{2}\right)$

$\mathrm{a}=$ acceleration of vehicle $\left(\mathrm{m} / \mathrm{s}^{2}\right)$

$\mathrm{v}=$ velocity of vehicle $(\mathrm{m} / \mathrm{s})$

$\mathrm{R}_{\text {regen }}=$ recuperation rate $(\%)$

$\mathrm{E}_{\text {total }}=$ total braking energy $(\mathrm{J})$

$E_{\text {bat,regen }}=$ energy charged to the battery while braking $(\mathrm{J})$

\section{Introduction}

There are many regulations that affect vehicle emissions. Moreover, the high cost trend of coal as a fuel continues. Because fuel economy is closely related to vehicle emissions, it is important to enhance the fuel economy of vehicle. Many companies and countries have developed various vehicle types commercially. Among these systems, the extendedrange electric vehicle (E-REV) is an electric vehicle concept that has a light engine to allow an extended driving range. Such vehicles are similar to series plug-in hybrid vehicles schematically. And it has characteristics of both an Electric vehicle (EV) and a hybrid electric vehicle (HEV). ${ }^{1}$ One of the most important features of these vehicles, based on electricity, is their ability to recover significant amounts of braking energy in a process known as regenerative braking. ${ }^{2}$ Among various methods to improve fuel economy, ${ }^{3-5}$ recovering the braking energy and reusing it can significantly improve the fuel economy of a vehicle which is subject to frequent braking events such as city bus. ${ }^{6-9}$ The more driving motor operates widely as generator, the more braking energy can be absorbed. However, it isn't realistic in terms of performance for components. This study proposes three regenerative braking torque maps as the constraint to limit excessive current of battery. Two type simulations are conducted to evaluate effect of regenerative braking for E-REV bus according to characteristic of driving cycle. One is a simulation while applying proposed torque maps. The other is a simulation while applying full regenerative braking. Results of the former are compared with those of the later. This process allows the calculations of the difference in the fuel economy between the two simulations. The characteristics of 19 driving cycles are also analyzed to find the relationship between these characteristics and the fuel economy of the vehicle according to driving cycle in this study. 


\section{Target Vehicle System}

\subsection{Extended-Range Electric Vehicle Bus}

The target vehicle system is an extended-range electric vehicle (EREV) bus which has a determined driving cycle. Hence, each component, such as the battery and the generator, can be determined according to the target driving distance during the development process. Additional generation can extend the limited driving range. Schematically, this system is similar to a series plug-in hybrid bus. The battery capacity of an E-REV is greater than that of series plug-in hybrid vehicles and is in fact very close to that of an electric vehicle (EV). Fig. 1 shows this system configuration. It includes two driving motors for propulsion and an engine for generation. It also has a battery as a power source. As mentioned above, each component is specified according to the target vehicle performance with the application of certain equations. ${ }^{10,11}$ The capacity of the driving motor is determined by the vehicle's maximum speed, its grade ability, and the desired acceleration rate of the vehicle. These values are $100 \mathrm{~km} / \mathrm{h}, 20 \%$ at $20 \mathrm{~km} / \mathrm{h}$ and $80 \mathrm{~km} / \mathrm{h}$ for 40 seconds, respectively, satisfying the needs for city buses. The capacity of the battery is determined by the allelectric range (AER). The AER for a city bus is $30 \mathrm{~km}$, which is the stochastic driving distance from Seoul in South Korea. The capacities of the engine and generator are determined by the amount of additional power required to sustain a state of charge (SOC) of the battery when the vehicle drives according to its set driving cycles. Table 1 shows the vehicle specifications satisfying these vehicle performances levels. To evaluate the fuel economy, a forward simulator is developed using Autonomie. ${ }^{12,13}$ It is made by Argonne National Laboratory in the USA and is based on Matlab/Simulink.

\subsection{Control Strategy for Target Vehicle System}

Hybrid system such as E-REV must have some means of control of the power distribution between the engine and the battery. There are many power distribution control strategies which can be used for E-

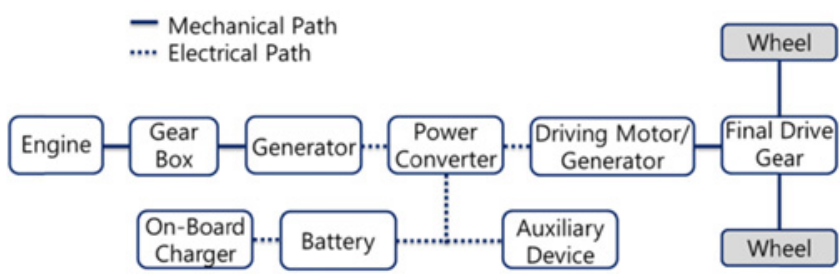

Fig. 1 Vehicle system configuration

Table 1 Vehicle specification

\begin{tabular}{cc}
\hline \multicolumn{2}{c}{ Vehicle specification } \\
\hline Air density $\left(\mathrm{kg} / \mathrm{m}^{3}\right)$ & 1.293 \\
\hline Frontal area $\left(\mathrm{m}^{2}\right)$ & 6.6 \\
\hline Air drag, $\mathrm{C}_{\mathrm{d}}$ & 0.8 \\
\hline Rolling resistance & 0.01 \\
\hline Weight, CVW $(\mathrm{kg})$ & 12000 \\
\hline Transmission efficiency & 0.95 \\
\hline Tire radius $(\mathrm{m})$ & 0.478 \\
\hline Vehicle power source components \\
\hline Engine maximum power $(\mathrm{kW})$ & 120 \\
\hline Motor maximum power $(\mathrm{kW})$ & $240(120 \mathrm{~kW}$ of each) \\
\hline Battery capacity $(\mathrm{Ah})$ & 120
\end{tabular}

REV like plug-in HEV. ${ }^{14-17}$ In this study, a thermostat control strategy is applied. It is also known as an engine on/off strategy. The engine on/ off operation is determined by the SOC of the battery. Its advantages are relatively simple and rely on the optimal engine operating point. ${ }^{2}$ To sustain the SOC of the battery, the engine operates when the SOC of the battery is lower than $20 \%$ and engine stops when it is higher than $20 \%$ as an instance. In this study, only this charge-sustaining mode (CS mode) is considered when the SOC of the battery is fully depleted below $20 \%$.

\subsection{Regenerative Braking for Target Vehicle System}

Regenerative braking system is the most important feature of vehicles based on electricity. When a conventional vehicle brakes, the majority of the braking energy dissipates as heat in the air. Vehicles based on electricity, such as EVs, HEVs and E-REVs can store this dissipated braking energy in the battery through regenerative braking. Recovering the braking energy and reusing it can significantly improve the fuel economy of a vehicle which is subject to frequent braking events such as a city bus. ${ }^{6-9}$ The more regenerative braking operates, the greater the improvement in fuel economy which can be obtained theoretically. When the driving motor as the generator operates in all feasible fields without any constraint to the greatest extent possible, the vehicle can acquire the greatest amount of additional energy. To confirm the effect of regenerative braking for an E-REV bus, simulations were conducted depending on the application of regenerative braking. One of the simulations assumes regenerative braking is absolutely impossible. The other assumes regenerative braking works fully without any constraints except for minimum torque of driving motor. They are called no regenerative braking and full regenerative braking in this research. Table 2 shows fuel economy of each case. These values are reasonable when the fuel economy for conventional diesel bus is $2.15 \mathrm{~km} / \mathrm{L}^{18}$ and they are simulations. Table 2 also shows the maximum effect of regenerative braking for E-REV bus by comparing two cases. The difference in the fuel economy was found to be $48.4 \%$. As a result, the fuel economy for an E-REV bus can differ considerably according to the application of regenerative braking because this type of vehicle has large electric components.

\subsection{Simplified Regenerative Braking Torque Maps}

As shown in the results above, it is best to ensure that the operating regions of the driving motor are as broad as possible. However, there are technical performance limitations of these components. Hence, regenerative braking needs to be regulated by restricting the torque. In this study, regenerative braking is limited by several constraints. These are the vehicle speed, accelerator pedal signal, brake pedal signal and voltage of the battery. Considering these constraints, simplified regenerative braking torque maps are proposed. These maps can limit the regenerative braking torque to utilize confined fields of the driving motor. The mechanical braking system supplies an insufficient amount

Table 2 Effect of regenerative braking

\begin{tabular}{cc}
\hline Simulations & Fuel economy $(\mathrm{km} / \mathrm{L})$ \\
\hline No regenerative braking & 2.43 \\
\hline Full regenerative braking & 3.61 \\
\hline Difference $(\%)$ & 48.4 \\
\hline
\end{tabular}


of braking torque when the required braking torque is greater than the available regenerative braking torque. The simplified torque maps consist of 2D and 3D lookup tables. They can be tuned easily and understood intuitively. Figs. 2-4 show the simplified regenerative braking torque maps. Fig. 2 shows the simplified torque map depending on the vehicle speed when there is no accelerator pedal

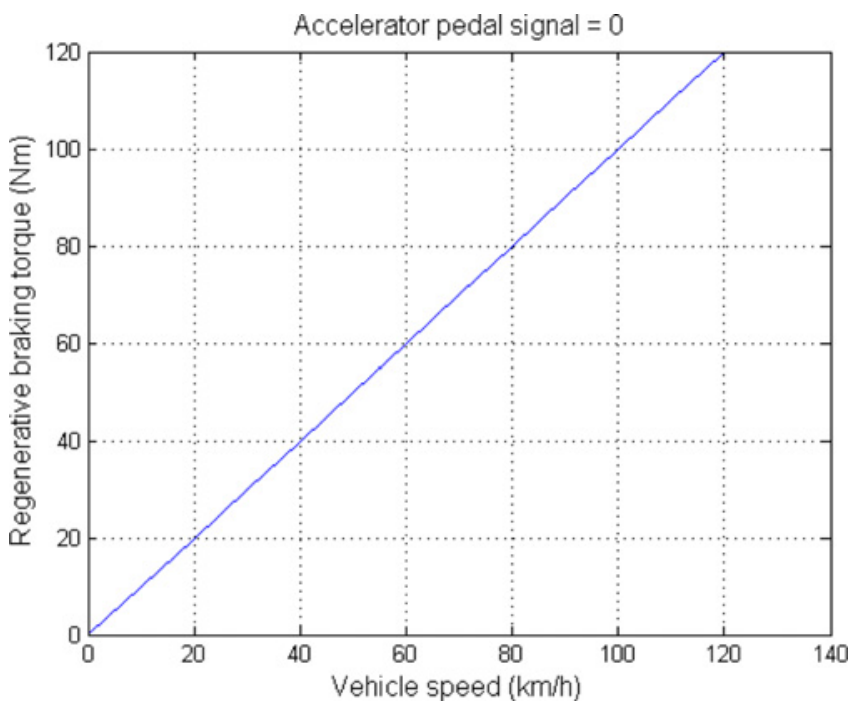

Fig. 2 Simplified torque map 1

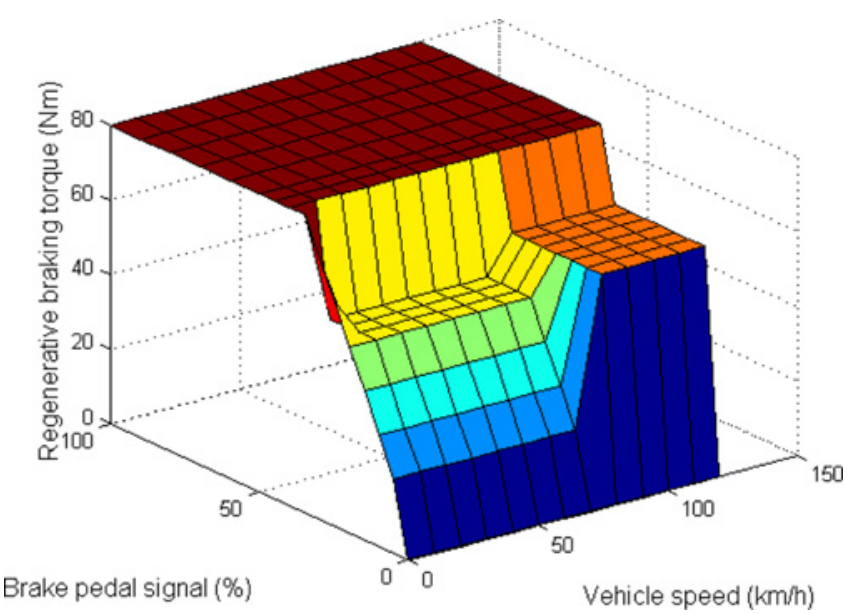

Fig. 3 Simplified torque map 2

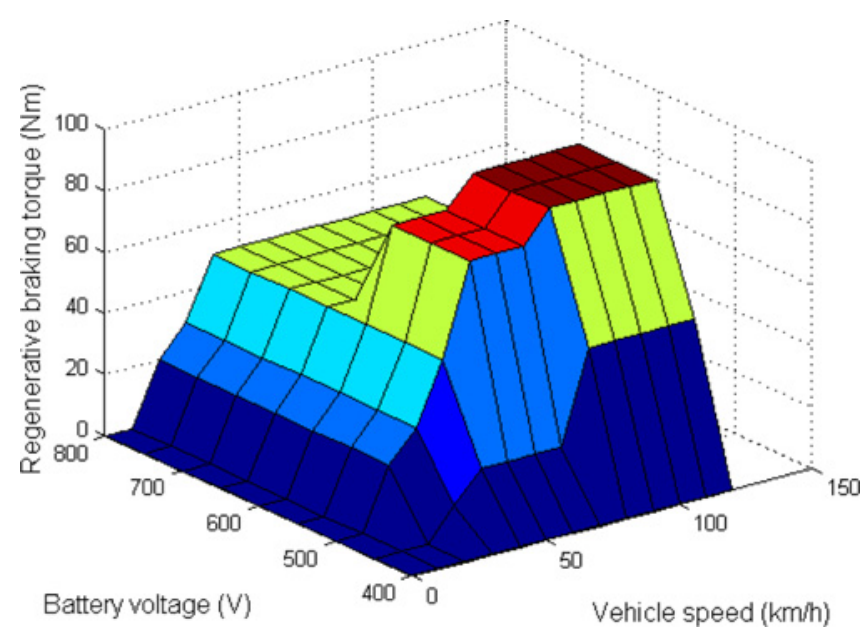

Fig. 4 Simplified torque map 3 signal. It is called simplified torque map 1 . Because control of the driving motor is difficult when the motor speed is slow and there are safety problems, the regenerative braking torque is forward proportional to the vehicle speed. Fig. 3 shows the simplified torque map depending on the brake pedal signal and the vehicle speed. It is called simplified torque map 2 . The brake pedal signal indicates the driver's intention to brake. The regenerative braking torque increases with an increase in this signal. Although it is similar to simplified torque map 1 in terms of how the vehicle speed is considered, it differs from simplified torque map 1 because the vehicle speed and brake pedal signal are considered at the same time. Also, Fig. 4 shows the simplified torque map depending on the battery voltage and the vehicle speed. It is called simplified torque map 3. Because a low battery voltage indicates that charging is required, a relatively large amount of regenerative braking torque is required. As with simplified torque map 2 , the vehicle speed is considered simultaneously. By regulating the torque, the battery can be used safely in terms of performance. However, these values are defined by basic experimental processes and thus are approximatively assumed here. Hence, they can be defined more clearly in additional experiments. This study only proposes a method and the necessity of regulating the regenerative braking torque. In the simulations, all maps are applied at once.

\section{Analysis of Driving Cycle}

As mentioned above, the target vehicle is a transit city bus. Hence, 19 driving cycles categorized as city cycles having below $80 \mathrm{~km} / \mathrm{h}$ of maximum vehicle speed are determined. The characteristics of each driving cycle are analyzed to obtain the inclination because the fuel economy differs according to the driving cycle. The average speed, average acceleration, average deceleration and aggressiveness are calculated. The aggressiveness can describe the aggressive driving

Table 3 The characteristic of driving cycle

\begin{tabular}{ccccc}
\hline $\begin{array}{c}\text { Driving } \\
\text { cycle }\end{array}$ & $\begin{array}{c}\text { Average } \\
\text { speed } \\
{[\mathrm{km} / \mathrm{h}]}\end{array}$ & $\begin{array}{c}\text { Max speed } \\
{[\mathrm{km} / \mathrm{h}]}\end{array}$ & $\begin{array}{c}\text { Average } \\
\text { acceleration } \\
{\left[\mathrm{m} / \mathrm{s}^{2}\right]}\end{array}$ & $\begin{array}{c}\text { Aggressiveness } \\
{\left[\mathrm{m} / \mathrm{s}^{2}\right]}\end{array}$ \\
\hline No.1 & 19.38 & 57.32 & 0.12 & 0.15 \\
\hline No.2 & 25.97 & 66.20 & 0.14 & 0.18 \\
\hline No.3 & 20.24 & 39.81 & 0.26 & 0.18 \\
\hline No.4 & 25.54 & 74.68 & 0.17 & 0.19 \\
\hline No.5 & 24.91 & 64.41 & 0.15 & 0.21 \\
\hline No.6 & 19.78 & 40.87 & 0.27 & 0.22 \\
\hline No.7 & 24.75 & 71.68 & 0.15 & 0.22 \\
\hline No.8 & 24.71 & 53.50 & 0.27 & 0.23 \\
\hline No.9 & 26.43 & 58.75 & 0.23 & 0.23 \\
\hline No.10 & 24.14 & 46.80 & 0.28 & 0.23 \\
\hline No.11 & 21.10 & 49.90 & 0.27 & 0.24 \\
\hline No.12 & 22.32 & 56.20 & 0.27 & 0.25 \\
\hline No.13 & 19.51 & 42.17 & 0.32 & 0.25 \\
\hline No.14 & 20.65 & 53.00 & 0.28 & 0.26 \\
\hline No.15 & 28.94 & 63.36 & 0.26 & 0.27 \\
\hline No.16 & 17.10 & 40.48 & 0.24 & 0.27 \\
\hline No.17 & 30.50 & 59.70 & 0.33 & 0.28 \\
\hline No.18 & 23.17 & 58.80 & 0.30 & 0.28 \\
\hline No.19 & 27.49 & 56.40 & 0.38 & 0.31 \\
\hline & & & &
\end{tabular}


patterns of real-world driving schedules. One of the factors determining the driving characteristics is the average of acceleration. However, it is difficult to find a correlation with the fuel economy theoretically. Thus, the aggressiveness is defined based on the energy required for acceleration. The vehicle mass of a commercial vehicle such as a bus is a critical factor when estimating the fuel economy. ${ }^{19-21}$ Hence the vehicle mass is normalized to calculate the degree of aggressiveness. The aggressiveness of a driving cycle can be described by considering the acceleration and speed of the vehicle as defined by Eq. (1). The degree of aggressiveness refers to how harsh the driving cycle is.

If the aggressiveness of the driving cycle is high, the driving cycle is harsh. This condition is linked to the consumption of high amounts of fuel. Table 3 shows the characteristics of all driving cycles including aggressiveness. It can also confirm their maximum vehicle speeds are less than $80 \mathrm{~km} / \mathrm{h}$. The characteristics vary according to the driving cycle. Although the average speed is high, the aggressiveness is low when No.2 of driving cycles is considered. On the other hand, No.16 of driving cycles has low average speed and high aggressiveness.

$$
A g g=\int(a \cdot v)^{+} d t / \int v d t
$$

\section{Simulation to Evaluate the Fuel Economy}

\subsection{Process of the Simulation}

In each forward simulation, the final SOC of the battery differs according to the driving cycle. To compare results of the driving cycles, the fuel economy needs to be modified by considering the final SOC of the battery due to the trade-off between the final SOC of the battery and the fuel economy. When the final SOC of the battery is high, the vehicle can be considered to have greater potential fuel economy. On the other hand, the vehicle can be considered as having lower potential fuel economy when the final SOC of the battery is low. To modify the fuel economy, several simulations are performed iteratively. The initial SOC of the battery is set for every simulation. Also, the delta SOC and the delta fuel consumption can be calculated. The delta SOC is the gap between the initial SOC and the final SOC of the battery. The delta fuel consumption is the gap between each case and the standard case when a specific case is standard. Because the delta SOC and the delta fuel consumption exist in a linear relationship, this is used for the modification of the fuel economy. ${ }^{22,23}$ Fig. 5 and Table 4 show the results of the modification when utilizing this relationship. Using the red dot in Fig. 5, the amount of fuel consumed is adjusted, which allows the corrected fuel economy to be obtained. According to the regenerative braking method applied, two simulations are conducted. The first is a simulation in which regenerative braking is applied without any constraints, and the second is a simulation with the simplified torque maps applied. The fuel economy of the latter is compared with that of the former. The difference in the fuel economy is important in this research because this value indicates how effective the proposed maps are with respect to the fuel economy related to fully regenerative braking.

\subsection{Result of the Simulation}

To analyze the effect of the simplified regenerative braking torque maps, the results of the driving motor and the battery are checked. In the simulation with full regenerative braking applied without any constraints, the driving motor operates in all regions of the maximum and minimum torque lines. On the other hand, in the simulation with the simplified regenerative braking torque maps applied, the driving motor operates only in limited regions.

Fig. 6 shows the driving motor operating points based on the motor efficiency map. Positive torque refers to the driving torque and negative torque refers to the regenerative braking torque. These results show the limited regenerative braking torque with the simplified torque maps. These constraints can limit the battery performance. To avoid excessive

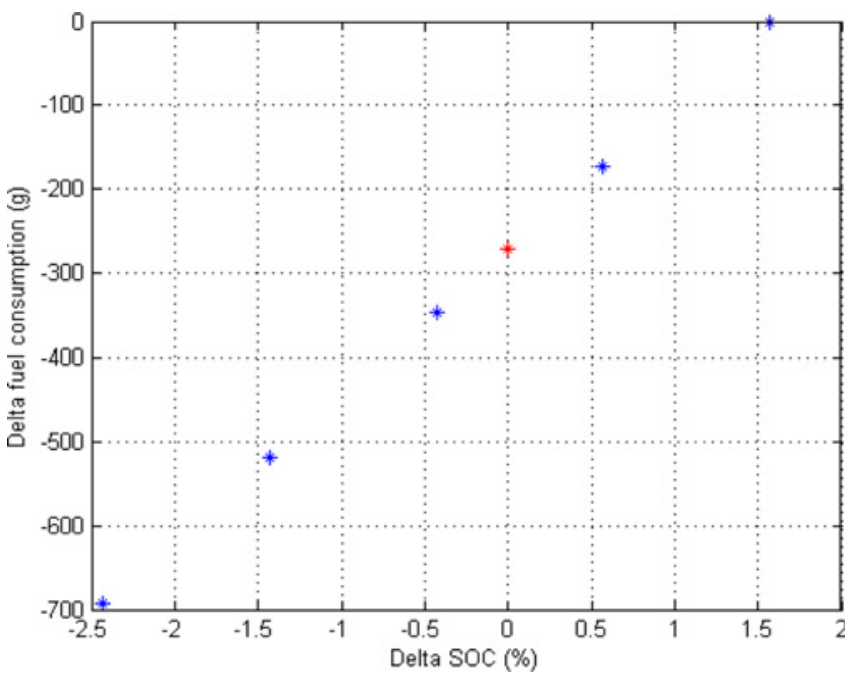

Fig. 5 Delta SOC and delta fuel consumption

Table 4 Results of simulations for correcting fuel economy

\begin{tabular}{cccccc}
\hline Case & 1 & 2 & 3 & 4 & 5 \\
\hline Initial SOC (\%) & 18 & 19 & 20 & 21 & 22 \\
\hline Final SOC (\%) & 19.6 & 19.6 & 19.6 & 19.6 & 19.6 \\
\hline $\begin{array}{c}\text { Fuel consumption } \\
\text { (g) }\end{array}$ & 2697.2 & 2526.8 & 2356.1 & 2180.7 & 2007.6 \\
\hline $\begin{array}{c}\text { Delta fuel } \\
\text { consumption (g) }\end{array}$ & 0 & -170.4 & -341.1 & -516.5 & -689.5 \\
\hline
\end{tabular}

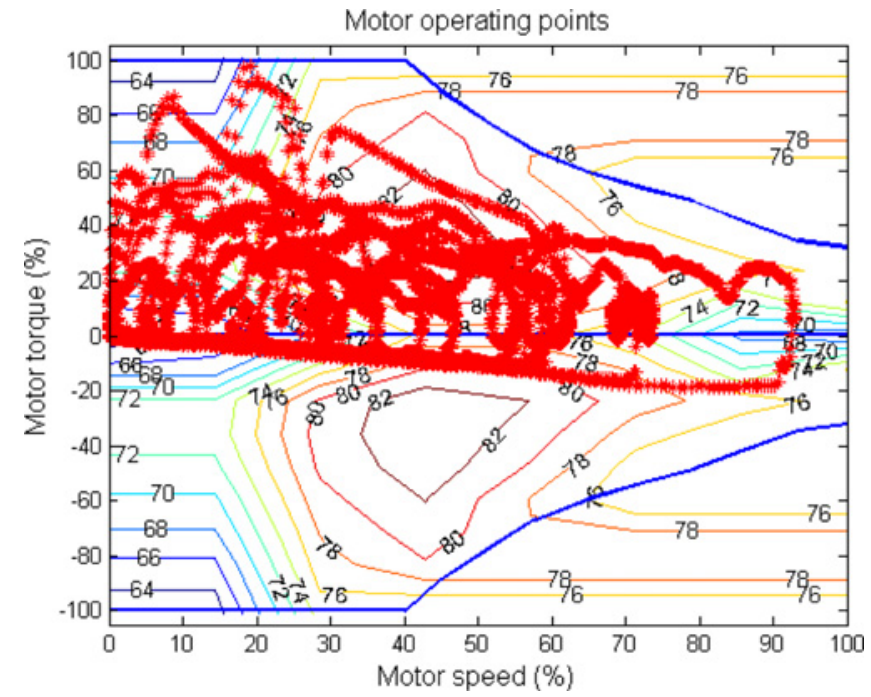

Fig. 6 Driving motor operating points limited by the simplified torque maps 
conditions such as a high charging current of the battery, these maps stabilize the charging process. Fig. 7 shows the current of the battery in each simulation. Red and green lines show boundary of the current rate. Red line means $1 \mathrm{C}$ of the current rate and green line is $2 \mathrm{C}$ of the current rate. Although the current rate of the battery is $2 \mathrm{C}$ in the simulation with full regenerative braking applied without any constraints, this can be problem when battery performance levels are not guaranteed. When the simplified torque maps are applied, the charging current of the battery is limited to $1 \mathrm{C}$ and stable results are obtained relatively. According to performance of battery, these differences of results can be remarkable.

In addition, in this paper the recuperate rate is defined by Eq. (2). $\mathrm{E}_{\text {total }}$ refers to the total braking energy. It includes mechanical braking and regenerative braking. $E_{\text {bat,regen }}$ is the amount of energy charged to the battery when regenerative braking operates. The recuperation rate refers to how much braking energy is absorbed by the battery when all conversion losses are considered. Table 5 shows the recuperate rates and the corrected fuel economy for each simulation. This fuel economy is an average of 19 driving cycle. When the simplified torque maps are applied, the recuperation rate is $12.2 \%$ and the fuel economy is $2.71 \mathrm{~km} / \mathrm{L}$. Considering the technology level at this time, these values are more realistic than those of the simulation with full regenerative braking applied without any constraints.

$$
R_{\text {regen }}=\frac{E_{\text {bat, } \text { regen }}}{E_{\text {total }}} \times 100
$$

The trends between the differences in the fuel economy and the characteristics of the driving cycles are analyzed to confirm the possibility of improving the fuel economy. The difference in the fuel
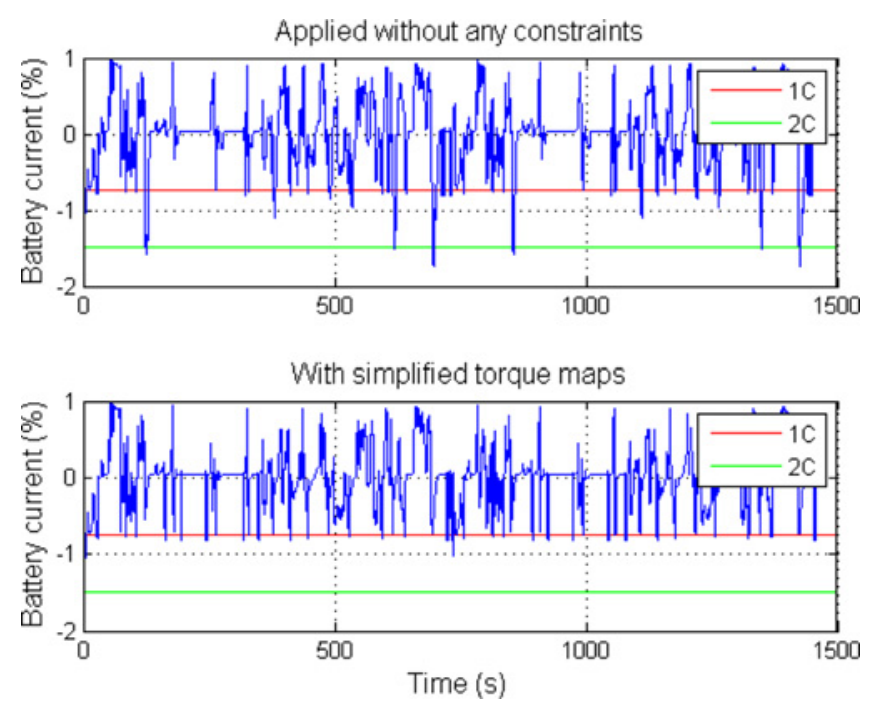

Fig. 7 The current of the battery in the simulations

Table 5 Results for each simulation

\begin{tabular}{ccc}
\hline Simulation & Recuperation rate $(\%)$ & Fuel economy $(\mathrm{km} / \mathrm{L})$ \\
\hline $\begin{array}{c}\text { Full regenerative } \\
\text { braking }\end{array}$ & 51.0 & 3.61 \\
\hline $\begin{array}{c}\text { Regenerative } \\
\text { braking with } \\
\text { simplified torque } \\
\text { maps }\end{array}$ & 12.2 & 2.71 \\
\hline
\end{tabular}

economy is calculated according to the results of the two simulations above. Vehicle weight is also considered as CVW $(12000 \mathrm{~kg})$ and GVW (15500 kg). Fig. 8, Fig. 9 and Fig. 10 are results of CVW. Fig. 8 shows the average vehicle speed and the differences in the fuel economy values. While it is difficult to find a clear relationship, the

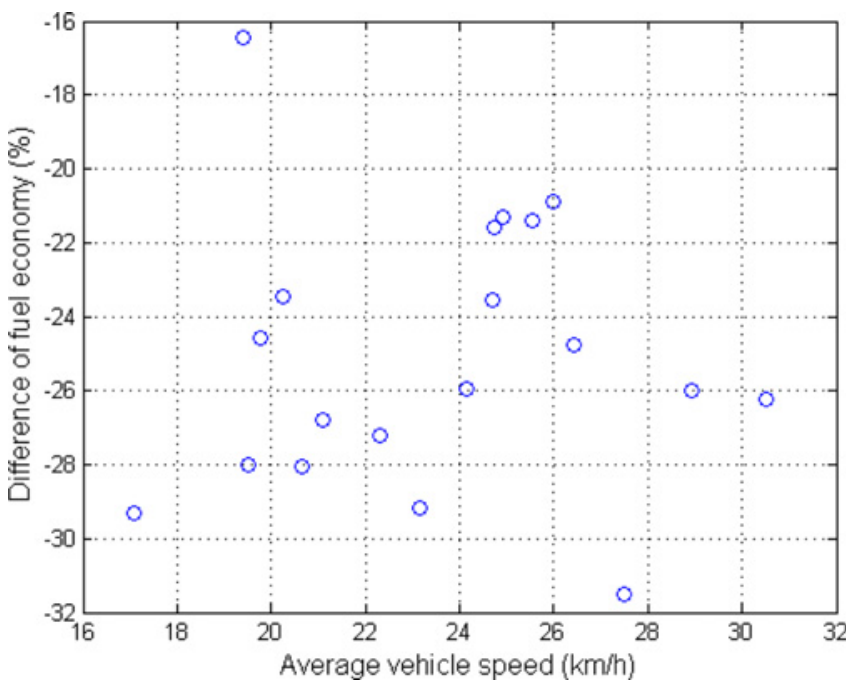

Fig. 8 Average vehicle speed and difference of fuel economy

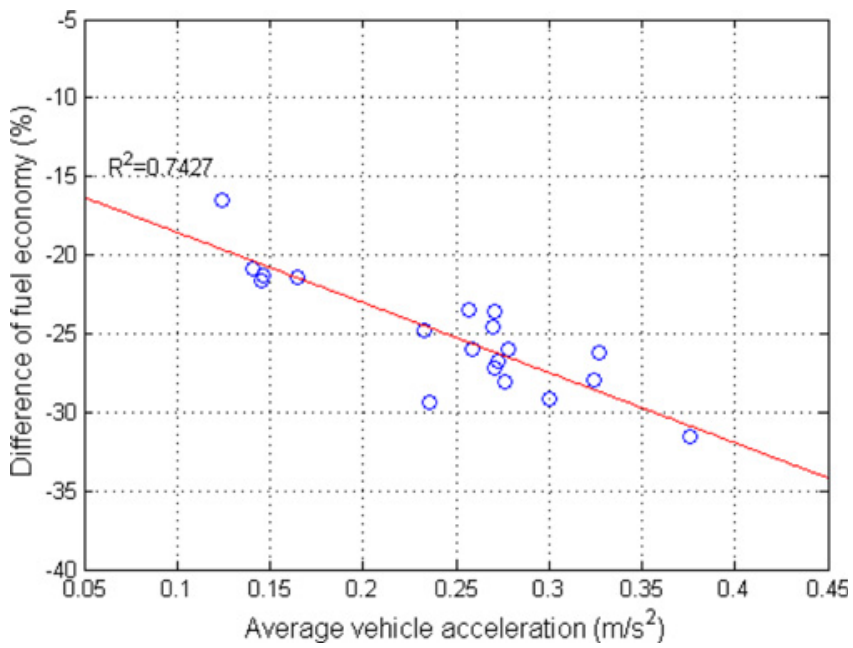

Fig. 9 Average vehicle acceleration and difference of fuel economy

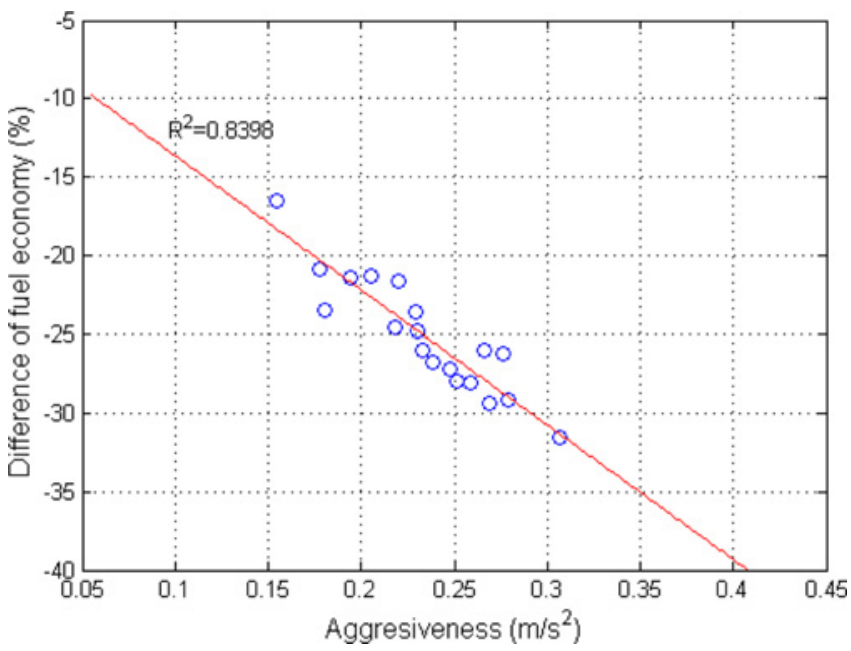

Fig. 10 Aggressiveness and difference of fuel economy 
results pertaining to the acceleration and aggressiveness are very different. Fig. 9 and Fig. 10 show the acceleration and aggressiveness results, depicting linear relationship. The coefficients of determination are 0.7427 and 0.8398 respectively. When vehicle weight is GVW, they have lower inclination than those of CVW. However, it is certainly correct that acceleration and aggressiveness have a linear relationship. The greater the acceleration or the aggressiveness is, the greater the difference in the fuel economy is. Between these, the aggressiveness is more correlated than the acceleration. Hence, to improve the fuel economy up to the level of full regenerative braking, simplified torque maps can be tuned properly according to the aggressiveness of the driving cycle and vehicle weight.

\section{Conclusions}

In this study, the E-REV bus system is defined and the capacities of the vehicle components are determined according to target vehicle performance levels. A forward simulator for an E-REV bus was created by Autonomie based on Matlab/Simulink. Using the forward simulator, the effect of regenerative braking was analyzed. The results of a simulation with full regenerative braking applied without any constraints were compared to those of a simulation with no regenerative braking. With regenerative braking, the fuel economy results differed by as much as $48.4 \%$. However, considering the performance of the battery and practical limitations, operation of the driving motor was constrained by the application of the simplified torque maps introduced in this study. The characteristics of 19 driving cycles were then analyzed to determine the relationship between the characteristics of the driving cycle and the fuel economy values. The results of the simulation with the simplified torque maps applied were compared to those of a simulation with full regenerative braking, after which the differences in the fuel economy were calculated. The driving motor and current of the battery were checked when the simplified torque maps were applied. The results of the recuperation rate and the fuel economy were $12.2 \%$ and $2.71 \mathrm{~km} / \mathrm{L}$, respectively. Among the characteristics of the driving cycles, the acceleration and the aggressiveness showed a linear relationship with regard to the difference in the fuel economy. Consequently, the degree of aggressiveness of the driving cycle and the difference in the fuel economy exist in a linear relationship. Although different vehicle weight made different coefficient of determination, this inclination between the characteristic of driving cycle and the difference of fuel economy was same. This result can be used to develop power distribution control strategies with regenerative braking models to improve fuel economy levels.

\section{ACKNOWLEDGEMENT}

This work was supported by the Industrial Strategic Technology Development Program (10033126) under the Ministry of Trade, Industry \& Energy, Republic of Korea and the National Research Foundation of Korea (NRF) grant funded by the Ministry of Science, ICT \& Future Planning (MSIP) (No. 2009-0083495)

\section{REFERENCES}

1. Shin, D.-H. and Lee, B.-H., "Global Market Forecasts and Technology Issues of Plug-in HEV,” Auto Journal, Vol. 33, No. 10, pp. 20-25, 2011.

2. Ehsani, M., Gao, Y., and Emadi, A., "Modern Electric, Hybrid Electric, and Fuel Cell Vehicles: Fundamentals, Theory and Design," CRC Press, $2^{\text {nd }}$ Ed., pp. 411-431, 2010.

3. Choi, S., Ko, K., and Jeung, I., "Optimal Fuel-Cut Driving Method for Better Fuel Economy," International Journal of Automotive Technology, Vol. 14, No. 2, pp. 183-187, 2013.

4. Ko, J., Ko, S., Kim, I., Hyun, D., and Kim, H., "Co-Operative Control for Regenerative Braking and Friction Braking to Increase Energy Recovery without Wheel Lock," International Journal of Automotive Technology, Vol. 15, No. 2, pp. 253-262, 2014.

5. Kim, N., Lohse-Busch, H., and Rousseau, A., "Development of a Model of the Dual Clutch Transmission in Autonomie and Validation with Dynamometer Test Data," International Journal of Automotive Technology, Vol. 15, No. 2, pp. 263-271, 2014.

6. Khajepour, A., Fallah, S., and Goodarzi, A., "Electric and Hybrid Vehicles: Technologies, Modeling and Control - A Mechatronic Approach,” Wiley, pp. 233-235, 2014.

7. Gao, Y., Chen, L., and Ehsani, M., "Investigation of the Effectiveness of Regenerative Braking for EV and HEV," SAE Technical Paper, 1999.

8. Sangtarash, F., Esfahanian, V., Nehzati, H., Haddadi, S., Bavanpour, M. A., et al., "Effect of Different Regenerative Braking Strategies on Braking Performance and Fuel Economy in a Hybrid Electric Bus Employing Cruise Vehicle Simulation," SAE Technical Paper, Paper No. 2008-01-1561, 2008.

9. Bao, R. and Stobart, R., "Study on Optimization Regenerative Braking Control Strategy in Heavy-Duty Diesel Engine City Bus using Pneumatic Hybrid Technology," SAE Technical Paper, Paper No. 2014-01-1807, 2014.

10. Lee, D., Kim, N., Jeong, J., Park, Y., and Cha, S., "Component Sizing and Engine Optimal Operation Line Analysis for a Plug-in Hybrid Electric Transit Bus," International Journal of Automotive Technology, Vol. 14, No. 3, pp. 459-469, 2013.

11. Lee, D., Jeong, J., Park, Y., and Cha, S., "The Component Sizing Process and Performance Analysis of Extended-Range Electric Vehicles (E-REV) Considering Required Vehicle Performance," Transactions of the Korean Society of Automotive Engineers, Vol. 21, No. 2, pp. 136-145, 2013.

12. Anderson, D. and Slezak, L., "What Can Autonomie Do for You?" Proc. of the IEEE on Vehicle Power and Propulsion Conference, pp. $1-153,2011$.

13. Choi, J., Lee, D., Jeong, J., Lee, H. Y., Park, Y., et al., "Development of Forward Simulator for Analysis of E-REV Bus Performance," Proc. of KSAE Spring Conference, pp. 1753-1756, 2013. 
14. Sharer, P., Rousseau, A., Karbowski, D., and Pagerit, S., "Plug-in Hybrid Electric Vehicle Control Strategy: Comparison between EV and Charge Depleting Options," SAE Technical Paper, Paper No. 2008-01-0460, 2008.

15. Wirasingha, S. G. and Emadi, A., "Classification and Review of Control Strategies for Plug-in Hybrid Electric Vehicles," IEEE Transactions on Vehicular Technology, Vol. 60, No. 1, pp. 111-122, 2011.

16. Jeong, J., Lee, D., Kim, N., Zheng, C., Park, Y.-I., et al., "Development of PMP-Based Power Management Strategy for a Parallel Hybrid Electric Bus,” Int. J. Precis. Eng. Manuf., Vol. 15, No. 2, pp. 345-353, 2014.

17. Kim, J., Lee, C., and Park, Y., “Analysis of Fuel Economy for Series Plug-in Hybrid Electric Bus according to Engine Operation Strategy Based on Simulation," Transactions of the Korean Society of Automotive Engineers, Vol. 22, No. 5, pp. 102-107, 2014.

18. Kim, Y., Lee, Y., Choi, K., Jeong, D., Lim, Y., et al., "Development of a Diesel-Hybrid Bus and Measurement of Fuel Consumption and Exhaust Gas Emission," Proc. of KSAE Autumn Conference, pp. 2876-2881, 2011.

19. Choi, J., Jeong, J., Lee, D., Shin, C., Park, Y., et al., "Analysis of Fuel Economy Sensitivity for Parallel Hybrid Bus according to Variation of Simulation Input Parameter," Transactions of the Korean Society of Automotive Engineers, Vol. 21, No. 6, pp. 92-99, 2013.

20. Lee, D., Seo, H., Park, Y., Lim, W., and Cha, S., "System Efficiency Analysis for Next Generation Eco-Friendly Vehicles with Aggressiveness of Real-World Driving Schedules," Proc. of KSAE Autumn Conference, pp. 3178-3183, 2010.

21. Jeong, J., Lee, D., Shin, C., Jeong, D., Min, K., et al., "Comparison of the Fuel Economy of Series and Parallel Hybrid Bus System using Dynamic Programming," Transactions of the Korean Society of Automotive Engineers, Vol. 21, No. 1, pp. 92-98, 2013.

22. Zheng, C., Shin, C. W., Park, Y., and Cha, S. W., "Evaluation of Hybridization in FCVs based on Equivalent Fuel Consumption," Transactions of the Korean Society of Automotive Engineers, Vol. 19, No. 5, pp. 143-147, 2011.

23. Zheng, C., Oh, C., Park, Y., and Cha, S., "Fuel Economy Evaluation of Fuel Cell Hybrid Vehicles based on Equivalent Fuel Consumption," International Journal of Hydrogen Energy, Vol. 37, No. 2, pp. 1790-1796, 2012. 